\title{
Divertimentos e educação do corpo no protestantismo de Benjamin Franklin (1682 -1791)
}

Amusements and education of the body in Protestantism of Benjamin Franklin (1682 -1791)

Divertimientos y educación del cuerpo en el protestantismo de Benjamin Franklin (1682-1791)

\author{
Narayana Astra Van Amstel \\ Universidade Federal do Paraná (Brasil) \\ http://orcid.org/0000-0002-8707-2423 \\ http://lattes.cnpq.br/8205771844342227 \\ narayana.astra@gmail.com \\ Evelise Amgarten Quitzau \\ Universidad de la Republica Uruguay (Uruguai) \\ http://orcid.org/0000-0001-9789-6488 \\ http://lattes.cnpq.br/2702602895497887 \\ eveliseaq@yahoo.com.br \\ Marcelo Moraes e Silva \\ Universidade Federal do Paraná (Brasil) \\ http://orcid.org/0000-0001-6640-7952 \\ http://lattes.cnpq.br/4996091053878759 \\ marcelomoraes@ufpr.br
}

\section{Resumo}

$\mathrm{O}$ artigo tem como objetivo compreender os elementos que caracterizaram a postura do protestantismo norte-americano em relação aos divertimentos e à educação do corpo. Apesar de existirem muitas obras sobre Benjamin Franklin poucas exploraram a relação das suas contribuições com uma prescrição sobre os divertimentos e educação do corpo. As fontes utilizadas foram legislações da Pensilvânia e os escritos de Franklin. As análises evidenciam que, se por um lado as leis constituíam um quadro de condenação da ociosidade e dos divertimentos, por outro, os escritos trazem observações favoráveis a atividades como o xadrez e práticas físicas, justificando estes divertimentos a partir de uma moral utilitarista.

Palavras Chaves: Ética protestante. Divertimentos. Tempo livre. América. História. 


\begin{abstract}
The purpose of this paper is to comprehend the elements that characterized the posture of north American Protestantism regarding amusements and the education of the body. Although there are many works on Benjamin Franklin few have explored the relation of their contributions with a prescription on the use of free time and the education of the body. The sources were Pennsylvania legislations and the writings of Franklin. The analysis evidence that, if on one hand the laws constituted a set of interdictions regarding idleness and amusements, on the other hand Franklin's writings brought favorable mentions about activities such as chess and athletic practices, justifying based on a utilitarian moral.
\end{abstract}

Keywords: Protestant ethics. Amusements. Free time. America. History.

\title{
Resumen
}

El objetivo de este artículo es comprender los elementos que caracterizaron la postura del protestantismo norteamericano respecto a las diversiones y a la educación del cuerpo. A pesar de existir varias obras sobre Benjamin Franklin, pocas han explorado la relación de sus contribuciones con una prescripción sobre divertimentos y educación del cuerpo. Las fuentes utilizadas fueron legislaciones de Pensilvania y los textos escritos por Franklin. Los análisis evidencian que si por un lado las leyes constituían un cuadro de condenación de la ociosidad y de los divertimentos, por otro los escritos traen observaciones favorables a actividades como ajedrez y prácticas físicas, justificándolos a partir de una moral utilitarista.

Palabras-clave: Ética protestante. Divertimientos. Tiempo libre. América. Historia. 


\section{Considerações Iniciais}

O espaço que os divertimentos ocuparam na sociedade americana colonial já foi alvo de pesquisa de estudiosos como Dulles (1965), Struna (1988) e Overman (2011). De maneira genérica, pode-se falar que as colônias eram ambientes hostis devido à presença de animais selvagens, ataques indígenas, escassez de produtos, distância da metrópole europeia, território desconhecido, dentre outros fatores (KARNAL, 2007), o que tornava o uso dos divertimentos pelos americanos um tanto conturbado.

Os europeus que imigravam para a América do Norte, em sua maioria ingleses puritanos, procuravam tornar a vida colonial próspera e segura para a comunidade. Disso dependia a conduta a ser adotada pelos cidadãos, a qual era determinada por leis pautadas em uma rígida moral religiosa de cunho protestante na maior parte das colônias (JABLE, 1974; OVERMAN, 2011). Os divertimentos não eram vistos com bons olhos pelos primeiros protestantes desde o século XVII, principalmente pelo ramo calvinista ${ }^{1}$ (OVERMAN, 2011), por conta de acreditarem que a vida de qualquer indivíduo deveria ter seu tempo ocupado exclusivamente por atividades laborais e religiosas. Dessa maneira, divertir-se era entendido como um pecado, uma forma de se alienar da vocação que cada fiel era chamado a cumprir durante sua vida como parte da missão delegada espiritualmente.

Tais características parecem não ter sido diferentes na colônia da Pensilvânia, comunidade fundada por protestantes em 1681, pelo quaker William Penn, tal como relata Karnal (2007). Existem leis do período colonial que mostram como a moral era marcada por cerceamentos ao considerado mau uso do tempo livre (JABLE, 1974; OVERMAN, 2011; AMSTEL, et. al. 2019). Nesse sentido, a moral protestante vislumbrava tanto no labor quanto no ócio a realização espiritual do indivíduo. Era necessário que todo tempo fosse destinado ao resguardo espiritual. Os divertimentos pareciam não auxiliar na redenção do indivíduo e nem indicavam uma forma de contribuição para a comunidade (DULLES, 1965; OVERMAN, 2011, AMSTEL, et. al. 2019). Torna-se natural pensar, portanto, que quando protestantes legislaram sobre a ocupação do tempo nas colônias, estabeleceram repreensões ao considerado ao não bom uso de seus momentos livres.

Entre as atividades que eram praticadas no período colonial, pode-se destacar jogos de azar (cartas, dados e tabuleiros), adivinhação, jogos de pontaria (flechas, dardos e tiro), caçadas, pescarias, corridas (a pé, em carruagens ou montando animais - touros, cavalos, burros, etc), saltos, boliche, bilhar, bem como os blood sports - práticas que envolviam apostas em brigas de cães, galos e até ursos. Cabe também destacar a existência de danças e bailes (AMSTEL et. al, 2019). Para Struna (1988), essa vontade de cercear várias dessas atividades provinha principalmente dos gentlemen - cavalheiros, em geral de classe mais alta e com maior instrução - e de parte da classe média. Tinham preferência por atividades como o remar, a equitação e o pedestrianismo (GEMS; BORISH; PFISTER, 2017), mas podiam rejeitar práticas que eram comuns às classes sociais equivalentes de outros países. Um exemplo disso foi a rejeição aos teatros no período colonial da Filadélfia (MORGAN, 1966). Nesse sentido, nota-se indícios de que havia critérios não tão claros dentro da cultura colonial americana em relação à aceitação de determinados divertimentos, algo que exige análise para entendimento.

\footnotetext{
${ }^{1} \mathrm{O}$ protestantismo, iniciado por Lutero e aprofundado por Calvino, instituiu, dentre outras crenças, a noção de vocação para todos os seus membros (OVERMAN, 2011). Em um sentido diferente do catolicismo, que compreendia a vocação como o chamado para trabalho sacerdotal, o protestante interpretava que todos os fiéis deveriam realizar a missão que lhe foi dada por Deus através de sua própria profissão. Extinguia-se assim a figura clerical e todos os membros da igreja protestante deveriam dedicar suas vidas ao trabalho e espiritualidade. Disso decorre uma postura radical de trabalho, a qual Max Weber (2004) aponta como uma das causas sociais do capitalismo moderno.
} 
Para entender melhor isso, torna-se convidativo estudar uma figura muito conhecida da história americana, Benjamin Franklin², cidadão da Filadélfia (capital da Pensilvânia), que escreveu muitos textos ao longo do século XVIII que expunham sua visão particular a respeito do uso do tempo livre e divertimentos. Em princípio parece compartilhar da opinião protestante, sendo um crítico contumaz dos preguiçosos, ociosos e boêmios. Entretanto, uma análise mais acurada indica que Franklin dedicou muitas menções favoráveis as práticas atléticas e ao xadrez, divertimentos que considerava úteis em diferentes aspectos. Sendo um dos autores mais lidos da história americana na época (ISAACSON, 2015), torna-se interessante analisar sua obra para compreender essas posturas conflitantes entre os bons e maus divertimentos, bem como as formas de usar o tempo livre e os elementos educacionais nela presentes.

O presente artigo procura justamente tensionar a moral protestante, representada na legislação colonial, com os escritos de Franklin, um indivíduo que ora parecia estar alinhado com os preceitos religiosos de sua comunidade, ora apresentava novas formas de uso do tempo livre pautadas em uma postura utilitarista. Sendo assim, buscou responder a seguinte problemática investigativa: Como as noções de divertimentos e de educação do corpo estiveram presentes na obra Benjamin Franklin? Nesse sentido, estabeleceu-se como objetivo geral da pesquisa: compreender os elementos que caracterizaram a postura do protestantismo em relação aos divertimentos e a educação do corpo na obra de Benjamim Franklin. Por sua vez, os objetivos específicos são os seguintes: a) analisar como a moral protestante exemplificava-se nas legislações do período relativas ao controle dos divertimentos; b) investigar como uma lógica utilitarista presente na moral protestante implicou no controle de práticas de divertimento e nos elementos pedagógicos envolvidos. c) apresentar as noções que Benjamin Franklin atribuía para em seus escritos nas questões educacionais relacionadas aos divertimentos.

\section{Fontes}

O presente artigo fundamentou seus dados em fontes documentais oriundas de livros e leis selecionados para compreender aspectos da ética protestante americana no período de 1682 a 1791. Os textos separados como fonte para análise foram os seguintes:

1) 'Dialogue between Franklin and the gout': escrito em 1780 por Benjamin Franklin como uma peça cômica, em que o próprio autor se encontra num diálogo com sua doença de gota, que o afligiu ao final da vida. O texto retrata sua angústia pelo tempo desperdiçado com atividades sedentárias (inclusive o xadrez que tanto gostava) e que provocaram seu quadro de saúde deteriorado.

2) 'On the moral of Chess': redigido por Benjamin Franklin e publicado no periódico The Columbian Magazine em dezembro de 1786, consiste em um ensaio que apresenta as virtudes morais que podem ser extraídas da prática de enxadrismo, bem como expõe os comportamentos a serem adotados pelos jogadores na condução de uma partida.

3) 'The autobiography of Benjamin Franklin': escrito dos principais acontecimentos da vida de Franklin sob sua própria perspectiva autobiografica, publicado em 1791.

\footnotetext{
${ }^{2}$ Nascido no dia 17 de janeiro de 1706 em Boston e falecido em 17 de abril de 1790 na Filadélfia, Benjamin Franklin ocupou seus 84 anos de vida com afazeres dos mais diversos. De produtor de velas na firma do pai a político influente na Filadélfia, Franklin atravessou ocupações como impressor (jornais, almanaques, livros e até papel-moeda), inventor, funcionário público, diplomata, embaixador, constituinte, escritor, jornalista, editor e representante colonial (FRANKLIN, 1791; ROBERTS, 1991; ISAACSON, 2015). Como cientista e inventor, destacou-se principalmente pela produção dos primeiros modelos de para-raios, oriundos de sua pesquisa com tempestades, marcadamente conhecidas pelas histórias do empinamento de pipas em noites chuvosas infestadas de relâmpagos.
} 
4) 'Poor Richard's Almanack': uma das mais famosas publicações de Franklin, consistia em edições anuais repletas de ditados, anedotas e conselhos dados pelo autor sob o pseudônimo de Richard Saunders. A data de cada publicação é variada. A fonte utilizada é uma compilação de todos os volumes feita em 1999, por Jon Craft. As publicações originais ocorreram a partir de 1732, estendendo-se por diferentes períodos ao longo da vida do intelectual norte-americano.

5) 'Proposals relating to Education of Youth in Pensilvania': folheto de Benjamin Franklin publicado na Filadélfia em 1749, onde defendeu uma educação diferenciada para a colônia da Pensilvânia. Destaca-se a inclusão de exercícios físicos como componente curricular, ainda no século XVIII.

6) 'The Great Law': publicado em 1682, consiste em uma autêntica constituição de leis para a colônia da Pensilvânia. Foi referida ao longo do texto como 'Blue Law'3 . Tal fonte é acrescentada à pesquisa por contribuir na contextualização do período a que Franklin escrevia, representando a moral religiosa dos puritanos.

\section{O utilitarismo em Benjamin Franklin}

Benjamin Franklin foi fruto de uma educação calvinista, tendo em vista que sua família e a comunidade na qual crescera eram dessa orientação religiosa. No entanto, durante a maior parte de sua vida, declarou-se um deísta ${ }^{4}$ (ISAACSON, 2015). Cabe destacar que não era nos mesmos moldes dos deístas europeus, lembrados principalmente na figura de Diderot, mas um deísmo frankliano, por assim dizer, pois era essencialmente pragmático e utilitarista em sua crença acerca do divino. Para Franklin, acreditar na existência de uma entidade suprema e atenta à humanidade era algo útil para a sociedade em geral, pois as virtudes valorizadas por esse ser superior formariam a moral que embasaria a vida em comunidade.

Como o deísmo clássico acreditava que a entidade superior não se importava com as ações humanas e relegava à natureza o papel de controle da criação divina (AQUINO, 2013), Franklin enxergava nessa teologia um pressuposto para surgir um relativismo moral que poderia ser prejudicial para a sociedade (ISAACSON, 2015). Ao mesmo tempo, não concordava com o calvinismo no qual fora criado, que alegava uma predestinação do recebimento de Graça para alguns poucos eleitos, pois isso implicaria na desqualificação das boas obras, que Franklin tanto acreditava serem o ponto forte das religiões, a base utilitária da crença (ISAACSON, 2015). Pode-se dizer que o deísmo de Franklin, portanto, englobava tanto o que ele considerava bom (leia-se útil) no deísmo clássico, com alguns valores do puritanismo calvinista, rejeitando o que considerava ruim (leia-se inútil, não-prático) nas duas teologias.

A respeito do utilitarismo, Franklin foi um filósofo que em muitos aspectos pareceu ter preparado o terreno filosófico dessa corrente de pensamento americana. A corrente filosófica do pragmatismo originou-se oficialmente com os pensadores William James e Charles Sanders Peirce ao final do século XIX, e que possui como nome mais proeminente o filósofo John Dewey (SOUZA, 2010). Entretanto, Isaacson (2015) considera que as origens dessa escola filosófica residem nas contribuições de Benjamin Franklin. De uma forma mais ampla o pragmatismo

\footnotetext{
${ }^{3}$ Tal como era referida na época, assim como muitas outras leis (JABLE, 1974). Deve-se ao tipo de papel em que eram publicadas, no caso, de coloração azulada.

${ }^{4} \mathrm{O}$ deísmo, fruto do iluminismo, origina-se no século XVII e consiste em uma filosofia religiosa que despreza o sobrenatural, o dogma religioso e a ideia de textos religiosos relevadores. A maior parte dos deístas acredita que a razão humana é o atributo máximo para confirmação da existência do divino, em que a experiência da natureza indicaria sua presença. Sua ausência de rituais e tradições na relação com o sobrenatural é a razão de seu declínio e dá forças para o ateísmo moderno se fundamentar (VARTANIAN, 1949).
} 
defende essencialmente a ideia de que a produção de qualquer tipo de conhecimento deve obrigatoriamente ligar-se a um resultado prático. Já o utilitarismo, segundo aponta Sandel (2015) é uma linha de pensamento que atribui aos valores morais o bem-estar coletivo e das partes envolvidas, tendo caráter normativo. Desse modo, de acordo com o autor, uma ação terá sua utilidade deduzida de quanta felicidade ela produziu para os indivíduos. Nesse sentido, Isaacson (2015) afirma existirem evidências do pragmatismo e utilitarismo nos textos de Franklin.

\section{Virtudes infusas em um jogo - controle e utilidade nos divertimentos de Franklin}

Antes de apontar os enunciados favoráveis de Franklin a determinados elementos da cultura física $^{5}$, é necessário primeiramente indicar uma possível contradição nos seus escritos em relação ao ato de se divertir. Aparentemente o autor condenava o tempo "desperdiçado" em atividades como jogos, como pode ser visto no texto Settling Down presente em sua biografia (FRANKLIN, 1791). Nesse texto Franklin afirmou que não gastava tempo em tavernas, jogos e divertimentos: "Ler era o único divertimento que eu me autorizava. Eu não gastava nenhum tempo em tavernas, jogos ou brincadeiras de nenhuma natureza" (FRANKLIN, 1791, p.81).

Haviam também conselhos dados à população em geral em 'Poor Richard Almanack' (FRANKLIN, 1732), momento no qual retratou que o jogo era algo que diminuía a saúde e a ambição. Existem diversas outras passagens nas quais condenava diversões que em sua opinião nada de útil acrescentam à vida dos indivíduos:

Deveria ser considerado abusivo um governo que cobra de seu povo um décimo de seus ganhos para que seja empregado em seus serviços. Mas a preguiça nos cobra muito mais, se considerarmos tudo que é gasto na indolência absoluta, com o que se investe em ocupações ociosas ou divertimentos que nada acrescentam. A preguiça traz essas doenças, encurtando a vida (FRANKLIN, 1791, p.136).

Em outro capítulo de sua biografia, intitulado Early Life, Franklin mostrou um arrependimento do período de juventude em que gastou tempo em excesso indo às peças de teatro e outros divertimentos, desperdiçando o dinheiro que ganhava trabalhando:

Imediatamente comecei a trabalhar em Palmer, depois em uma famosa gráfica em Bartholomew Close, e ali continuei por quase um ano. Era muito empenhado, mas gastei, junto com Ralph, boa parte dos meus recursos indo a peças de teatro e outros lugares de diversão. Juntos gastamos toda as minhas moedas. (...) Esta foi outra das grandes erratas da minha vida, que eu gostaria de corrigir se fosse viver de novo (FRANKLIN, 1791, p.63).

Com tantas críticas aos momentos de ociosidade, pode parecer que Franklin se recriminasse por ocupar o tempo com divertimentos, preferindo uma vida ascética e sem permissões para sentir prazer. A leitura parecia ser a única atividade tolerada por ele como divertimento, mas provavelmente porquê tinha utilidade para o desenvolvimento intelectual. Das vezes que afirma ter frequentado ambientes de diversão, demonstrava um profundo arrependimento.

\footnotetext{
${ }^{5}$ Cultura física é um conceito utilizado por Kirk (1999) para referir-se a um conjunto de práticas voltadas à manutenção, representação e regulação do corpo, sendo representadas em três práticas codificadas e institucionalizadas: o esporte, as recreações e os exercícios. No cenário acadêmico sul-americano, a conceituação tem sido operacionalizado recentemente, sendo dividida em esporte, divertimentos (em um sentido mais amplo, para além de apenas recreações físicas) e ginástica (REGIANNI, 2016; FURTADO; QUITZAU; MORAES E SILVA, 2018; MORAES E SILVA; QUITZAU, 2018; MORAES E SILVA; QUITZAU; SOARES, 2018; SCHARAGRODSKY, 2014; 2017).
} 
A postura de Benjamin Franklin estava em consonância com a moral protestante que preponderava na maior parte das colônias americanas do período, em que o puritanismo correspondia à fé majoritária (WEBER, 2004; KARNAL, 2007; OVERMAN, 2011). O desprezo à ociosidade e a ocupação do tempo com divertimentos na colônia da Pensilvânia, em que Franklin cresceu, tinha como representação máxima a 'Blue Law', conjunto de regras a serem seguidas por todos os habitantes da região em questão. Jable (1974) as classificou como uma proposta realizada por conselhos legislativos, organizados pelo governador quaker William Penn em 1680 e postas em vigor em 1682. Existiam artigos de lei direcionados diretamente ao controle de comportamentos relacionados aos divertimentos:

E que seja promulgado pela autoridade supracitada que qualquer um que introduzir ou frequentar, nessa província, tais esportes rudes e tumultuosos, bailes de máscaras, bullbaits e brigas de galo, serão devidamente responsabilizados como rompedores da paz e terão como pena, pelo menos, dez dias de prisão, realizando trabalhos forçados pesados, ou pagarão a multa de vinte xelins. (PENSILVÂNIA, 1682, p.4).

Cabe destacar aqui que os divertimentos considerados 'perturbadores' da ordem não eram apenas as práticas consideradas violentas, mas também certas danças e atividades rudes para o padrão de comportamentos da época. Portanto, não era apenas uma tendência civilizatória no sentido de diminuir os impulsos de agressividade e ampliar o controle da violência, tal como explicitado por Elias e Dunning (1992). Existia uma referência aos esportes 'rudes' e 'tumultuosos', bem como os bailes. Além das práticas citadas o documento prossegue em suas restrições: "(...) se qualquer pessoa for condenada por jogar cartas, dados, loterias ou outros jogos e esportes de natureza vã ou maligna, deverá pagar, por delito, a quantia de cinco xelins, ou sofrer prisão sob regime de trabalhos forçados pesados" (PENSILVÂNIA, 1682, p. 5).

Tendo em vista a moral materializada na Blue Law, o contexto filadelfense em que Franklin inseria-se era o de uma moral bastante rígida com jogos de azar, danças, práticas violentas, bailes e bebedeiras. A moral do período indicava que o remédio prescrito era o de privação da liberdade sob trabalhos forçados, capazes de reeducar o corpo transgressor para a vida em sociedade. A ociosidade, tão rejeitada pela moral local, também se mostrava evidente no pensamento de Franklin. O mesmo considerava que o tempo era algo precioso e que não deveria ser perdido com práticas inúteis, apenas para diversão e/ou satisfação pessoal. Uma de suas cartas, escrita em 1732, elencava uma série de indivíduos que apresentam comportamentos inúteis, indesejáveis e condenáveis do ponto de vista moral:

Várias vezes vi em seu jornal reflexões sobre nós, mulheres, por conta de ociosidade e extravagância, mas não me lembro de ter visto nem uma vez tais versões sobre os homens. Se estivéssemos dispostas a ser censoras, poderíamos fornecer exemplos suficientes. Eu poderia mencionar o Sr. Billiard, que perde mais do que ganha na mesa verde, e estaria preso há muito tempo, se não fosse por sua diligente esposa. Mr. Hustlecap, que, a cada dia de mercado, pelo menos, e muitas vezes durante todo o dia, deixa o seu negócio pelo barulho da half-coin ${ }^{6}$, num

\footnotetext{
${ }^{6}$ Aqui apresenta-se uma dificuldade de tradução: supõe-se que Franklin esteja referindo-se ao jogo Shove Half Penny, um divertimento aparentemente muito popular nos pubs ingleses entre os séculos XV e XIX (THE ONLINE GUIDE TO TRADITIONAL GAMES, 2019). Parece tratar-se de uma competição que envolvia precisão no lançamento de moedas em um tabuleiro de madeira, no qual as mesmas deveriam cair em determinados espaços que davam pontuações diferentes. Ao vencedor cabia recolher todas as moedas lançadas por si e por seus adversários. Pode-se supor que, ao menos na época que Benjamin Franklin escrevia, considerava-se um jogo de azar e devia ser, pelo tom da escrita, algo moralmente condenável.
} 
certo beco; ou o Sr. Finikin, que tem sete ternos diferentes de roupas finas e usa uma peça todos os dias, enquanto sua esposa e filhos estão em casa seminus; O sr. Crownhim, sempre sonhando com o tabuleiro de damas, e que não se importa com a maneira que o mundo tem tratado sua família, de forma que ele prefere só se dedicar ao jogo; Sr. Totherpot, o taberneiro; Mr. Bookish, o leitor sempre duradouro; Sr. Tweedledum, e vários outros, que são muito diligentes em qualquer coisa além de seus próprios negócios (FRANKLIN, 1844, p.538).

Acerca dessa passagem é preciso ressaltar que os nomes próprios utilizados por Franklin são sátiras, trocadilhos e/ou simples joguetes de palavras. Por exemplo, o pseudônimo que assina a carta analisada era o de Celia Single, cuja tradução em português seria Celia Solteira. Tal procedimento era uma constante na escrita frankliana, visto que quando escrevia em jornais na Pensilvânia, frequentemente assinava com o pseudônimo Silence Dogood (Silêncio Fazbem) (ISAACSON, 2015). No trecho acima reproduzido, encontram-se vários nomes que originalmente tinham uma intenção de satirizar, tal como Sr. Billiard (Sr. Sinuca), o taverneiro Totherpot (do verbo tottering, cambalear; Vira-Copos) e Sr. Bookish (refere-se a alguém que adora ler livros, principalmente os complexos; Rato de Biblioteca). Contudo, o ponto principal da passagem reproduzida é a influência da moral protestante nos enunciados de Benjamin Franklin. Essa privação de divertimentos, que se traduz também em um ascetismo, configurase como uma "virtude" protestante, tal como indicado por Overman (2011). A ascese parecia comungar também com outra virtude útil ao protestantismo, a moral de controle do tempo. Benjamin Franklin, por mais de uma vez, citava o tempo como algo a se perder ou ganhar. No 'Poor Richard's Almanack' (1732), um de seus primeiros ensinamentos era o de que tempo é dinheiro, ou seja, algo que poderia ser empreendido, investido, mas que se mal utilizado tornava-se o instrumento de condenação do indivíduo na sociedade.

Apesar de condenar alguns divertimentos abertamente, Franklin parecia não ter problemas com outras práticas, tais como xadrez e o nadar. Isso se deve ao fato de ele não os enxergar como meras brincadeiras e sim atividades sérias. Esse processo de inserção de seriedade aos elementos lúdicos já foi algo explorado exaustivamente por autores como Huizinga (2000), Guttmann (2004) e Overman (2011) e parece estar fortemente associado aos processos de maior racionalização de práticas de jogo e de divertimentos ocorridos nas sociedades secularizadas. Características como racionalização e controle permeavam, na perspectiva frankliana, atividades como o xadrez e práticas físicas, e poderiam ter potencial de explicação para o fato de não serem atividades consideradas inúteis em sua moral, como será observado nas fontes exploradas mais adiante. Acima de tudo isso, existia uma constante defesa de justificativas utilitárias para tais atividades.

O utilitarismo seria a condição sine qua non dentro do processo de justificação dos jogos no período em questão. Sua utilidade inicialmente justificava-se na recuperação do vigor físico despendido no trabalho laboral. Todavia, existia uma ampla rede de interdições, pois não eram admitidos divertimentos que fossem de natureza violenta, de apostas, bailes e similares. Pontos que inclusive foram observados por Max Weber (2004, p. 152) em seus estudos sobre a ética protestante:

os puritanos defendiam sua peculiaridade mais decisiva: o princípio da conduta de vida ascética. Na verdade, aliás, a aversão do puritanismo ao esporte não era uma questão simplesmente de princípio, mesmo entre os quakers. Apenas devia servir a um fim racional: à necessária restauração da potência física. Já como simples meio de descontrair e descarregar impulsos indisciplinados, aí se 
tornava suspeito e, evidentemente, na medida em que fosse praticado por puro deleite ou despertasse fissura agonística, instintos brutais ou prazer irracional de apostar, é evidente que o esporte se tornava pura e simplesmente condenável. O gozo instintivo da vida que em igual medida afasta do trabalho profissional e da devoção era, exatamente enquanto tal, o inimigo da ascese racional, quer se apresentasse na forma de esporte grã-fino ou, da parte do homem comum, como frequência a salões de bailes e tabernas.

Tendo por base a análise de Weber, nota-se que não bastava a uma atividade ser praticada por classes abastadas. Os "esportes grã-finos" jogados pelos ricos não necessariamente eram algo que moralmente seriam aceitos pelos protestantes norte-americanos. Os divertimentos precisavam estar, necessariamente, atrelados a uma ação motivada por fins racionais e utilitários. Os elementos de racionalismo e utilitarismo tornam-se ainda mais evidentes quando se dirige um olhar para o xadrez na perspectiva de Franklin. Existem textos em que ele condena esse divertimento e outros em que o glorifica.

\section{A moral do xadrez posta em xeque - o paradoxo do bem e mal expostos em um divertimento}

Em relação a uma análise do xadrez, os escritos de Benjamin Franklin acerca desse jogo são poucos, mas podem ter sido muito influentes nos Estados Unidos do século XIX ${ }^{7}$. Ao ler o texto 'On the Moral of Chess' observa-se que Franklin defendeu a tese de que o referido jogo de forma alguma seria apenas um mero divertimento, elencando três grandes virtudes que deveriam ser cultivadas por aqueles que quisessem se dedicar ao xadrez: previsão, circunspecção e cautela.

A previsão revelava-se como a capacidade na qual as consequências dos atos eram levadas em conta na questão da futuridade. Tal questão se evidencia na citação a seguir: "Se eu mover essa peça, quais serão as vantagens e desvantagens em minha nova situação?" (FRANKLIN, 1786, p. 19). A segunda era a da circunspecção, pois Franklin afirmava que, ao olhar ao tabuleiro e às jogadas do adversário, era possível aprender a melhor observar e considerar as perspectivas e circunstâncias das coisas (FRANKLIN, 1786). Por fim, a terceira aptidão a ser desenvolvida seria a da cautela, visto que as regras do xadrez obriga o jogador a mover a peça uma vez que a toque e impede que, uma vez feito o deslocamento, altere-se o movimento por outro que lhe agrade mais.. Sendo assim, Franklin defendia que esse jogo ensinava a virtude de agir com cuidado e paciência (FRANKLIN, 1786).

Ao identificar as três grandes virtudes ensinadas pelo xadrez, Benjamin Franklin lhe instilava uma utilidade prática, em consonância com sua filosofia utilitarista. O jogo aqui retratado auxiliava Franklin em suas metas a serem atingidas, isto é, de formar um indivíduo mais cauteloso, observador e visionário, atributos que considerava bons e que também eram valorizados no período. Pode-se refletir também que o acréscimo de virtudes morais a um jogo é fruto de um processo racionalizante de justificação para uma atividade que Franklin gostava de fazer. Para não ser moralmente condenado por seus semelhantes, o pensador norte-americano apontava virtudes no jogo do xadrez que o permitissem transformá-lo em uma atividade útil, que lhe renderia bons frutos, sendo assim algo digno de ocupar em seu tempo livre.

\footnotetext{
${ }^{7}$ Torna-se complexo mensurar a importância de curtos textos de um escritor famoso para a história do xadrez e a difusão desse jogo no além-mar. Entretanto, em 1999 o World Chess Hall of Fame concedeu um local de honra a Franklin por suas contribuições na difusão da modalidade, não só nos EUA, mas também pelo Moral of Chess ter sido o primeiro livro de xadrez publicado na Rússia, em 1791. (WORLD CHESS HALL OF FAME, 2018). Ademais, o presidente da United States Chess Federation, em 2001-2003, John McCray, dedicou um artigo em que apresenta todas as contribuições de Franklin para a implementação desse esporte na América. Segundo dados da Federação, o nome de Franklin foi o primeiro a ser rastreado como jogador de xadrez nos EUA, em uma passagem de sua biografia, datada de 1733 .
} 
Além dessas três virtudes principais que o xadrez proporcionava, o pensamento frankliano atribui a esse jogo a capacidade de não se desencorajar perante situações aparentemente ruins, a possibilidade de sempre procurar recursos e ter a esperança de mudanças favoráveis (FRANKLIN, 1786). Aqui se tem uma nova inserção de categorias virtuosas a um jogo, em sintonia com as 'virtudes' de racionalismo e estabelecimento de metas levantados e comentados por Overman (2011).

Ademais, Franklin advogava que o respeito às diversas condutas no andamento das partidas tornava o praticante de xadrez um indivíduo melhor. Se é possível observar no pensador norteamericano o ato de atribuir a um passatempo como o xadrez a possibilidade de despertar na condição humana valores essenciais à formação de caráter, questiona-se se Franklin foi um dos pioneiros dos futuros movimentos de cristianismo muscular do século XIX, que enxergavam nos esportes o potencial pedagógico e de florescimento das características desejadas por um cristão ${ }^{8}$. Para além disso, salienta-se que o ato de respeitar condutas era uma forma de autocontrole, no sentido adotado por Elias (2001), e quem não seguisse as regras do jogo seria considerado um indivíduo incivilizado e descontrolado. Nova evidência de justificação utilitarista do xadrez como divertimento aceitável: poderosa ferramenta de civilidade e autocontrole, marca de um amplo processo de educação do corpo, conforme ensina Soares (2014).

Ademais, cabe frisar que o xadrez é um jogo intelectual. O historiador francês Georges Vigarello (2008, p.353), quando trata dos jogos que eram costumeiramente alvos da crítica moral, percebe a distinção de três tipos:

O primeiro é aquele no qual a principal parte cabe ao espírito ou à habilidade, como são os jogos de xadrez, de damas, a péla. O segundo consiste unicamente no azar, como o jogo de dados, de cartas (...) O terceiro, que é um misto, depende em parte da perícia e em parte do azar, como o pique, o triunfo (jogo de cartas), o jogo de gamão.

No sentido exposto pelo historiador francês, é evidente que o xadrez, por ser um jogo de 'espírito', de habilidade intelectual, teria uma facilidade de aceitação pelo julgamento moral da sociedade. Porém, não poderia ser um xadrez que envolvesse prazer infrutífero e apostas, que fosse descontrolado e/ou tivesse qualquer outra atribuição que pudesse destruir sua capacidade de produzir as almejadas virtudes. Ademais, ressalta-se que Benjamin Franklin não enxergava com bons olhos um outro jogo de tabuleiro de natureza intelectual, o jogo de damas, tal como já demonstrado no texto anteriormente citado de seu pseudônimo jornalístico, Celia Single (FRANKLIN, 1844). Sendo assim, destaca-se que a atribuição de valores positivos por parte do intelectual americano não foi ampliada para outros divertimentos similares ao xadrez.

A segunda parte do texto 'On the moral of Chess' apresenta as condutas e as virtudes civilizadas que deveriam ser seguidas pelos praticantes:

(...) se seu adversário demora para jogar, você não deve apressá-lo, ou expressar qualquer desconforto em seu atraso. Você não deve cantar, assoviar, olhar para seu relógio, pegar um livro para ler, bater os pés no chão ou os dedos na mesa, ou qualquer outra coisa que atrapalhe sua atenção. Pois todas essas coisas desagradam; elas não mostram sua habilidade de jogar, mas sim sua ardilosidade e grosseria (FRANKLIN, 1786, p. 22).

O autocontrole do corpo durante o jogar xadrez é evidente em tal passagem. Através

\footnotetext{
${ }^{8}$ Segundo Watson, Weir e Friend (2005), o cristianismo muscular, formulado no século XIX, defendia essencialmente a ideia de que a participação em atividades esportivas orientadas poderia contribuir no molde do caráter e na aprendizagem de valores, muitas vezes enaltecendo características de vigor masculino, desejáveis à mocidade do referido período.
} 
das contribuições de Elias (2001), que analisou os manuais de civilidade da Europa prémoderna e observou que a educação dos costumes e comportamentos desejáveis pressupunham justamente a existência de uma sociedade grosseira e incivilizada e que carecia de tais ensinamentos, a tendência é imaginar o mesmo para o caso de Benjamim Franklin. Se o intelectual prescrevia que não se deveria cantar, assoviar, bater os pés no chão ou realizar qualquer outro comportamento indesejado, é de supor que isso ocorria quando indivíduos se punham a jogar xadrez. Atitudes desagradáveis, comportamentos indesejáveis de corpos ainda não educados, que denotavam a falta de civilidade e que deveriam ser evitados a qualquer custo. Era preciso pedagogizar o ato de jogar xadrez, tornando-o repleto de costumes mais regrados e controlados, que respeitassem o adversário e que conseguissem manter o corpo comportado, por mais que as horas demandassem ao organismo a vontade de se movimentar. Dessa forma, através de um divertimento como xadrez, seria possível educar o corpo, controlando-o, conforme evidenciou Vigarello (2008), ao explorar o contexto do século XVIII na Europa.

Em sentido oposto ao aqui até então retratado, próximo do fim de sua vida, no ano de 1780, Franklin publicou um texto de caráter humorístico denominado 'Dialogue between Franklin and the gout'. Nessa obra encontra-se o pensador sendo protagonista da peça, acometido por um agravamento da doença de gota (provocada por excessos na alimentação e falta de exercícios físicos), em que conversava com a personificação da enfermidade, tentando entender porque seu organismo chegou a tal estado. A doença acaba por evidenciar que Franklin, durante sua vida sedentária, prezou por divertimentos que não eram fisicamente ativos.

O que você faz depois do jantar? Caminhar pelos lindos jardins na companhia dos amigos que jantaram ao seu lado seria a decisão mais sensata; mas você preferia jogar xadrez, empregando de duas a três horas nisso! Essa foi sua recreação perpétua, a mais desaconselhável para qualquer homem sedentário, pois ao contrário de acelerar o movimento dos fluidos, a atenção rígida requerida acaba por retardar a circulação e obstruir as secreções internas (FRANKLIN, 1780, s.p.).

$\mathrm{Na}$ sequência de sua análise o intelectual norte-americano retratou em uma dramatização como seu comportamento desleixado acabou por afetar sua saúde: "Franklin: - O que eu fiz para merecer esses sofrimentos cruéis? Gota: - Muitas coisas; você comeu e bebeu muito livremente, e satisfez demais essas pernas em sua indolência" (FRANKLIN, 1780, s.p.). O costume de comer e beber demais já era, no século XVIII na Europa, um comportamento visto como incivilizado, descontrolado, tal como indicam Vigarello (2008) e Quellier (2011). Ao fim da peça, Benjamin Franklin prometia “(...) nunca mais jogar xadrez, exercitar-se diariamente e viver com temperança" (FRANKLIN, 1780, s.p.). Neste momento parece que o pensador americano não enxergava mais virtuosidades no xadrez, porém é evidente que escreveu isso devido às circunstâncias do sofrimento de sua doença, não apagando a importância dos seus escritos acerca dos valores do xadrez.

Entretanto, uma importante e interessante análise pode ser efetuada acerca dessa peça. O xadrez, por ser um jogo intelectual e, portanto, de caráter não-físico, foi mostrado como uma atividade sedentária. Como aponta Vigarello (2008), noções de exercício físico e suas relações com a saúde já estavam se constituindo desde o século XVI na Europa e acabaram por permear igualmente o período no qual Benjamin Franklin se inseria. A saúde perdida seria fruto de um desequilíbrio e o único culpado seria o próprio indivíduo que permitiu que sua dimensão corporal atingisse tamanho estado de degradação. Eliminava-se gradualmente as causas sobrenaturais de doenças e racionalizava suas origens e consequências.

Franklin, como um pensador inserido nesse período, também defendia a prevenção como melhor remédio para se evitar doenças como a gota. $\mathrm{O}$ mesmo se mostrava como o único 
culpado por sua condição na velhice, fruto de um estilo de vida que permeou toda sua vivência. Tratam-se de noções orgânicas da saúde, mais racionalizadas, que já permitem as associações entre os hábitos do corpo e seus efeitos no organismo. Ainda assim, Benjamin Franklin não sugeria que atividades intensas deveriam ser utilizadas para combater sua doença de gota. Bastariam as caminhadas com os amigos após as refeições. O exercício justifica-se na perspectiva do utilitarismo por ser uma ferramenta de combate ao sedentarismo.

Destaca-se também que o espaço para a prática de exercício ainda não exigia ambientes específicos de aprimoramento corporal. Seriam suficientes as caminhadas com os amigos, ou seja, provavelmente uma intensidade leve, a qual permitisse realizar uma conversa durante o esforço. Os apontamentos de Franklin parecem novamente inserir-se na lógica destacada por Vigarello (2008, p. 374) sobre o contexto francês:

O exercício higiênico deve ser simples, cotidiano; uma caminhada, algum trajeto. Daí sua aplicação sempre possível, sua versão comumente acessível. O exercício ainda não necessita de tempo nem de espaços especiais (...) O objetivo de um exercício saudável limita-se à agitação de humores, seu universo limita-se ao espaço cotidiano.

A leitura da obra de Franklin a respeito do xadrez realça o conceito de 'aversão confusa' apontado por Vigarello (2008), ou os paradoxos de aceitação/rejeição de jogos e divertimentos tal como exposto por Overman (2011). O xadrez seria útil, pois desenvolvia virtudes e habilidades. Ao mesmo tempo era entendido como ruim, visto que se tratava de uma prática sedentária, tomando o tempo de atividades que fariam bem para o organismo doente que carecia de exercício físico. Aquele que louvou um jogo como útil é o mesmo que o demonizou em outro momento.

\section{O corpo que aprende pelo movimento - preocupações pedagógicas em Benjamin Franklin}

Encontra-se nos textos de Benjamin Franklin uma clara proposta de educação do corpo, que ia de uma pedagogia para o autocontrole. Ação que ia muito além do simples respeito às regras e bons comportamentos dentro do jogo de xadrez. Tal premissa inclusive era algo recorrente nos ditados formulados pelo pensador, sempre indicando o autocontrole como uma virtude útil: "César não mereceu o carro triunfal mais do que aquele que conquistou a si mesmo" (FRANKLIN, 1732, p. 20); “(...) deixa teus vícios morrerem em ti” (FRANKLIN, 1732, p. 21). O domínio dos instintos mais animalescos no indivíduo, a negação dos prazeres da carne, o autocontrole perante os impulsos mais primitivos, toda uma noção de civilidade dos costumes estava se construindo no período em que Franklin viveu e acabaram se materializando com contundência em suas obras. Tudo relacionado ao corpo passava a ser observado pelo prisma do útil em oposição ao inútil.

O intelectual americano lembrava a todo momento que o indivíduo capaz de se autocontrolar comandaria os outros: "Observe todos os homens; a si mesmo, muito mais" (FRANKLIN, 1732, p. 27). Esse autocontrole seria ampliado e reforçado pela vida social. Overman (2011) salienta que os olhares de vigilância entre as comunidades protestantes estariam associados à criação da Nova Jerusalém na própria Terra. $\mathrm{O}$ autor salienta que, se não fossem efetuadas as necessárias mudanças, tanto individuais quanto coletivas, a sociedade não se salvaria e poderia levar para a danação conjuntamente o indivíduo que nela se inseria. Nesse sentido, para Franklin, olhar para si e para os outros tratava-se de um processo conjunto, que visava a salvação tanto individual quanto da comunidade. Era necessário que o indivíduo possuísse autocontrole, mas que frequentemente fosse lembrado de seguir tais condutas por conta dos olhares vigilantes da moral dominante. 
Evidentemente, isso exigia um amplo processo de educação do corpo, o que seria mais simples de aprender durante a juventude. Foi por isso que, para as crianças, Franklin defendia: "Deixe a primeira lição de seu filho ser a obediência, e a segunda poderá ser o que você quiser" (FRANKLIN, 1732, p.24 - tradução livre). A mentalidade do período advogava que a criança era um ser imperfeito e incompleto (VIGARELLO, 2008). Sendo assim, Franklin acreditava que o controle do corpo infantil facilitaria o processo educacional, que seria muito mais árduo se executado na idade adulta. Tais noções já permeavam obras como a de John Locke ${ }^{9}$, autor a que Benjamin Franklin estava muito familiarizado (ISAACSON, 2015), bem como o pensamento de Jean-Jacques Rousseau ${ }^{10}$.

Ainda que as fontes elencadas não apontem de forma mais contundente se o intelectual norte-americano era um leitor de Rousseau, suas constantes defesas aos povos indígenas americanos da opressão por parte da metrópole colonial, podem ser um indicativo de assimilação dos conceitos de "bom selvagem" que perpassam toda a obra do pensador. Outros indicativos de sua aproximação à obra rousseauniana eram as constantes menções à natureza e à utilização das diversas práticas corporais nesse contexto. Como aponta Isaacson (2015), Franklin era amigo próximo de David Hume ${ }^{11}$, e esse por sua vez era muito ligado a Rousseau (inclusive tendo recebido-o em sua residência). Ainda assim, trata-se aqui de mera especulação se o pensador americano teria sido ou não influenciado por um filósofo tão conhecido na França do século XVIII. Entretanto, nesse sentido, destaca-se uma certa proximidade entre Franklin, Locke e Rousseau ao defenderem uma educação dos corpos das crianças.

Ainda no aspecto de educação dos corpos como algo útil ao desenvolvimento individual, não se pode ignorar um panfleto escrito por Benjamin Franklin em 1749. 'Proposals relating to the Education of Youth in Pensilvania' trata-se de um curto texto dedicado aos governantes do estado americano. Para o pensador, a Pensilvânia tinha sido colonizada por indivíduos que tinham recebido boa educação na Europa, entretanto, as limitações de tempo provocadas pelas tarefas de erigir uma estrutura colonial não lhes permitiram a adequação correta da educação local. Para sanar isso, Franklin prescrevia alguns elementos: "Para que possamos obter as vantagens advindas de um aumento de conhecimento, e evitar, tanto quanto possível, as consequências perniciosas que provocariam uma ignorância geral entre nós, as seguintes sugestões são oferecidas para a formação de um plano para a educação dos jovens de Pensilvânia (FRANKLIN, 1749, p. 1).

A falta de conhecimento, segundo indicam seus apontamentos, geraria problemas que afligiriam uma sociedade construída sem a presença de uma educação mais formalizada. Nesse sentido, tal questão passou a ser objeto de ponderação para Benjamin Franklin. A única saída seria a de criar um espaço para acomodar esses corpos jovens e ainda ignorantes num determinado espaço físico. Local esse que deveria ser regrado, hierarquizado e institucionalizado: "Que algumas pessoas de espírito público solicitem uma carta pela qual possam ser incorporadas com poder de erguer uma Academia para a educação da juventude,

\footnotetext{
${ }^{9}$ John Locke (1632-1704) foi um filósofo inglês, que defendia um Estado de poderes limitados e regido por uma constituição, respeitando os direitos naturais e negando as teorias de direito divino. Suas obras influenciaram a independências das colônias inglesas na América, bem como parte da Revolução Francesa (SCRUTON, 2007).

${ }^{10}$ Jean Jacques-Rousseau (1712-1778), nascido na Suíça, foi um importante escritor e filósofo do período na França, conhecido por obras como "Do Contrato Social" e "Emílio". Seu nome costuma ser associado às correntes do Iluminismo e do Romantismo. Para ele, o corrompimento do indivíduo residia nas instituições que o próprio ser humano fabrica, e sua libertação se daria por uma educação através da natureza, já que essa última estaria livre da ação humana (SCRUTON, 2007).

${ }^{11}$ David Hume (1711-1776), foi um filósofo escocês, marcadamente conhecido por seu profundo ceticismo e sua defesa do empirismo, em forte contraposição ao racionalismo cartesiano. Ainda assim, devido à sua natureza cética, é complexo associar Hume a uma escola de pensamento determinada, tanto que fora frequentemente utilizado como referência para sustentações argumentativas tanto por conservadores quanto por liberais (SCRUTON, 2007).
} 
governar a mesma, providenciar mestres, fazer regras, receber doações, comprar terras, e se integrarem na mesma" (FRANKLIN, 1749, p. 1).

Benjamin Franklin indicava que essa Academia deveria ser próxima à natureza, entretanto, observa-se que deveria ser construída em um ambiente controlado, salubre e nãoselvagem: "Que uma casa seja fornecida para a Academia, se não na cidade, a poucos quilômetros dela; que se situe em local alto e seco, e, se assim o estiver, que não seja longe de um rio, tenha um jardim, pomar, prado e um campo ou dois" (FRANKLIN, 1749, p. 3). Nas páginas subsequentes Franklin passou a discernir quais deveriam ser os conhecimentos e conteúdos a serem explorados nessa instituição. Evidencia-se aqui a recomendação da utilização de elementos que constituiriam posteriormente o discurso da cultura física:

Que, para mantê-los saudáveis e para fortalecer e tornar ativos seus corpos, eles sejam frequentemente exercitados em corridas, saltos, lutas $^{12}$ e natação. Que eles tenham hábitos peculiares para distingui-los de outros jovens, caso a Academia esteja dentro ou perto da cidade; por isso, entre outras razões, que seu comportamento possa ser o melhor observado (FRANKLIN, 1749, p. 3).

A primeira análise que poderia se empreender acerca dessa passagem é justamente acerca dessas práticas: saltar, nadar, lutar e correr, mas não de maneira livre. Os mesmos deveriam objetivar fortalecimento, proporcionar saúde, tornar ativos os corpos que realizariam tais atos. No confronto com a moral protestante da Pensilvânia, não seriam toleradas meros divertimentos descontrolados, desvinculados de utilidade prática. Franklin, condescendente com isso, propunha atividades úteis para um fim racional. Vigarello (2008, p.352), ao analisar o contexto francês, evidencia alguns destes elementos de controle:

O estatuto particular desses jogos físicos, sua liberdade, seu esmiuçamento, provocam inevitavelmente um interminável confronto com a autoridade: oposição do excesso e do constrangimento, da eferverscência e do poder (...) A desconfiança recai sobre a turbulência, talvez até sobre a suposta imoralidade de uma atividade julgada livre demais. Daí a tendência de regulamentá-la, mas também de inflecti-la e, algumas vezes, de suprimi-la. Portanto, a história desses jogos é a história de circunscrevê-los e de balizá-los. Ela é, em sentido mais amplo, a história de um insensível controle exercido sobre os corpos: uma vigilância supostamente capaz de conter melhor, no fim das contas, violências e paixões. Ela também é, por assim dizer, o desenvolvimento de práticas não partilhadas entre os sexos ou os grupos sociais, um modo bem concreto de confirmar pelo corpo distâncias ou distinções.

Evidencia-se, portanto, que Benjamin Franklin acabava por querer desenvolver uma juventude forte e ativa que realizasse atividades que as distinguissem das que não compusessem o quadro de alunos da Academia. "Que eles tenham hábitos peculiares para distingui-los de outros jovens (...) que seus comportamentos possam ser os melhores observados" (FRANKLIN, 1749, p. 3). Indício forte que, para o intelectual norte-americano, correr, pular, lutar e nadar eram práticas que possuíam potencial de inculcação de comportamentos bemvindos à formação de uma sociedade mais civilizada e por isso deveria fazer parte do processo

12 O termo wrestling aqui é referido como luta, por não saber qual forma de combate Franklin estava recomendando especificamente. Wrestling pode ser também associado a uma modalidade esportiva denominada luta livre. 
de educação do corpo da juventude norte-americana.

A saúde seria elemento de análise indispensável. Os elementos da cultura física que Franklin propunha para compor o conteúdo programático da Academia tinham função sanitária e em certo sentido higienista. Novamente Franklin se mostrou sintonizado com os discursos circulantes na Europa do século XVIII. Vigarello (2008, p. 367), ao pesquisar o contexto francês, expõe uma importante questão que pode ser relacionada com os pontos levantados pelo pensamento frankliano:

é impossível ignorar a vertente voluntariamente sanitária do exercício, esta prática da qual o autor espera um efeito sobre o corpo: saúde consolidada, órgãos reforçados. Não que todo jogador seja sensível a esta expectativa: o resultado está muito distante para ser um atrativo do jogo. Ele é suficientemente reconhecido, porém, para fundar desde sempre uma certeza, a de um ganho em vigor e em saúde obtido pelo movimento repetido.

Além do aspecto da saúde, vale lembrar que o período medieval via o 'jogar com o corpo' como sinônimo de diversão, impulso da carne, prazer e lembrança do pecado (VIGARELLO, 2008). Overman (2011) indica que a visão protestante não tolerava tais hábitos e costumes, rompendo com a lógica medievalista. Os divertimentos deveriam ser práticas orientadas para preparar o corpo para um objetivo concreto, produzindo sólidas recompensas morais. Ainda assim, salienta-se que repudiar certos jogos e valorizar outros, muitas vezes sem demarcar bem o que distinguirá os benefícios de um dos malefícios do outro, seria o que Vigarello (2008) chama de 'aversão confusa'. Como observado anteriormente, ocorriam mais interdições do que prescrições ao uso do corpo para diversão na moral protestante. Franklin parece tentar sanar tal 'confusão', estabelecendo objetivos, utilidades, fins que justifiquem o prazer, caso exista, já que o indivíduo estaria inserido em uma atividade controlada, regrada e civilizada, atendendo a um propósito almejado.

Poder-se-ia também pensar que tais práticas presentes na Academia tivessem a função de distração ou 'descarrego' do corpo perante a rotina de estudos, porém seria tremendo engano limitá-los a isso. Franklin deixava claro que todos os conteúdos (o que pressupõe incluir o nadar, correr, saltar e lutar) seriam úteis e indispensáveis para um processo maior de educação corporal: "Quanto aos seus estudos, seria bom se pudessem ser ensinados coisas que lhes sejam úteis (...) Mas a arte é longa e seu tempo é curto. Propõe-se, portanto, que aprendam as coisas que provavelmente serão as mais úteis às profissões as quais se destinam" (FRANKLIN, 1749, p. 5).

Vale lembrar que tal indicação de Benjamin Franklin para as práticas na Academia ressaltavam a questão da força. Para Vigarello (2008), a força no século XVIII era vista como um fator unificador. Tratava-se de um recurso orgânico específico escondido nos músculos e nervos. O jovem que adentrasse ao processo pedagógico da Academia frankliana estaria sujeito ao trabalho de desenvolver tal característica corporal. Uma juventude civilizada e educada seria útil para a formação da sociedade almejada por Franklin. Dentro da moral protestante em que o pensador estava inserido, era necessário que todas as atividades programadas estivessem amparadas em um resultado prático. Disso resultou suas contribuições educacionais para a formação da Universidade da Pensilvânia em 1740.

\section{Considerações Finais}

O período entre 1682 e 1791, de acordo com as fontes trabalhadas e os autores aqui consultados, era de rejeição aos divertimentos e ao mau uso do tempo livre. O corpo era alvo de interdições pelas legislações vigentes na colônia inglesa da Pensilvânia, fruto de uma rígida 
moral protestante que só via com bons olhos o trabalho profissional e o cultivo da fé. Diante dessa perspectiva, Benjamin Franklin nadou na contramão de alguns aspectos da moral protestante preponderante, e apresentou em seus escritos a justificativa de determinados divertimentos, considerados civilizados, controlados e úteis.

Aperfeiçoar a juventude da Pensilvânia, através de uma educação corpórea, era considerado uma preparação para o melhoramento de toda a comunidade, visto que os jovens cresceriam da forma que Franklin considerava a mais útil, prática e virtuosa. Tendo em vista as contribuições do pensador em relação ao xadrez, bem como as práticas físicas envoltas em uma finalidade pedagógica, fica saliente sua tentativa de controlar tais atividades e o corpo que as pratica. Fato que evidencia que o intelectual estava inserido na lógica que permeava a mentalidade da época. Franklin se apresentou como um indivíduo que permite compreender de fato como se materializavam as relações sociais que envolviam o corpo, jogos e divertimentos em uma cultura protestante norte-americana.

O pensador norte-americano, com sua originalidade e pioneirismo, era um indivíduo que não estava distante do contexto em que escrevia, muito pelo contrário. Era justamente pelo fato de estar inserido naquela comunidade tão religiosa e adversa às práticas físicas e divertimentos que Franklin notou a possibilidade de justificar de maneira utilitarista as atividades que lhe agradavam e que considerava importantes para o desenvolvimento da nação que almejava construir.

Vale ressaltar que, ao fim de sua vida, o texto acerca de sua doença de gota condenava o tempo gasto com o xadrez, atividade sedentária. Entretanto, da condenação de um divertimento, outro em seguida é apresentado: as caminhadas, úteis para a prevenção e recuperação da saúde deteriorada pelo sedentarismo e descontrole alimentar. Fica evidente que a lógica utilitarista e um poderoso discurso pedagógico se manifestam em todas as fontes retratadas no presente artigo. A moral protestante encaminhou os processos de racionalização no controle das práticas de divertimento, sempre justificando-os para um fim maior. Divertirse passou a ser então, de maneira gradual, algo aceitável no protestantismo norte-americana.

\section{Referências}

AMSTEL, Narayana Astra van; MARCHI JÚNIOR, Wanderley; SONODA-NUNES, Ricardo João; MORAES E SILVA, Marcelo. Divertimentos e a busca pelo controle: moderação protestante nas colônias norte-americanas (1633-1682). FairPlay - Revista de Filosofia, Ética y Derecho del Deporte, n.15, 2019 b.

AQUINO, Felipe. História da Igreja: Idade média. Cleofás: Lorena 2013.

DULLES, Foster Rhea. A history of recreation: Americans learn to play. New York: Appleton-Century-Crofts, 1965.

ELIAS, Norbert; DUNNING, Eric. A busca da excitação: desporto e lazer no processo civilizacional. Lisboa: Difel, 1992.

ELIAS, Norbert. A sociedade de corte - investigação sobre a sociologia da realeza e da aristocracia de corte. Rio de Janeiro: Zahar, 2001.

FURTADO, Heitor Luiz; QUITZAU, Evelise Amgarten; MORAES E SILVA, Marcelo. Blumenau e seus imigrantes: apontamentos acerca da emergência de uma cultura física (18501899). Movimento, v.24, n.2, p.665-676, 2018. https://doi.org/10.22456/1982-8918.81849 
FRANKLIN, Benjamin. Poor Richard's Almanck. 1732.

FRANKLIN, Benjamin. Proposals Relating to the Education of Youth in Pennsylvania. 1749.

FRANKLIN, Benjamin. Dialogue between Franklin and the gout. 1780.

FRANKLIN, Benjamin. On the Morals of chess. 1786.

FRANKLIN, Benjamin. The autobiography of Benjamin Franklin. 1791.

FRANKLIN, Benjamin. The works of Benjamin Franklin: containing several political and historical tracts not included in any former edition. 1844.

GEMS, Gerald; BORISH, Linda; PFISTER, Gertrud. Sports in American History: From Colonization to Globalization. Champagnie: Human Kinetics, 2017.

GUTTMANN, Allen. From ritual to record. New York: Columbia University Press, 2004.

HUIZINGA, Johan. Homo Ludens. São Paulo: Perspectiva, 2000.

ISAACSON, Walter. Benjamin Franklin: Uma vida americana. São Paulo: Companhia das Letras, 2015.

JABLE, Thomas. Pennsylvania's early Blue Laws: a Quaker experiment in the suppression of sport and amusements, 1682-1740. Journal of Sport History, v.1, n.2, p.107-121, 1974.

KARNAL, Leandro. História dos Estados Unidos: das origens ao século XXI. São Paulo: Editora Contexto, 2007.

KIRK, David. Physical culture, physical education and relational analysis. Sport, Education and Society, v.4, n.1, p.63-73, 1999. https://doi.org/10.1080/1357332990040105

MORAES E SILVA, Marcelo; QUITZAU, Evelise Amgarten. A cultura física na cidade de Curitiba: a emergência de uma pedagogia corporal (1899-1909). Revista Ciencias Sociales, v.27, n.40, 2018.

MORAES E SILVA, Marcelo; QUITZAU, Evelise Amgarten; SOARES, Carmen Lucia. Práticas educativas e de divertimento junto à natureza: a cultura física em Curitiba (1886-1914). Educação em Pesquisa, v.44, e178293, 2018. http://dx.doi.org/10.1590/s1678-4634201844178293

MORGAN, Edmund S. Puritan hostility to the theatre. Proceedings of the American Philosophical Society, v.110, n.5, p.340-347, 1966.

OVERMAN, Steven. The protestant ethic and the spirit of sport: How calvinism and capitalism shaped America's games. Macon: Mercer University Press, 2011.

PENSILVÂNIA. Great body of Law. 1682. Disponível em: http://www.phmc.state.pa.us/portal/communities/documents/1681-1776/great-law.html.

QUELLIER, Florent. Gula: história de um pecado capital. São Paulo: Editora Senac, 2011. 
REGGIANI, Andrés Horacio. Cultura física, performance atlética e higiene de la nación. El surgimiento de la medicina deportiva en Argentina (1930-1940). Historia Crítica, n.61, p.6584, 2016. http://dx.doi.org/10.7440/histcrit61.2016.04

ROBERTS, William Clifford. Benjamin Franklin's Poor Richard's Almanack and its maxims on physicians, medicine and nutrition. American Journal of Cardiology, v.68, n.6, p.703-706, 1991. https://doi.org/10.1016/0002-9149(91)90376-V

SANDEL, Michael. Justiça: o que é fazer a coisa certa. São Paulo: Editora José Olympio, 2015.

SCHARAGRODSKY, Pablo. Introducción. In: SCHARAGRODSKY, Pablo (Org.). Miradas médicas sobre la 'cultura física' en Argentina (1880-1970). Buenos Aires: Prometeo, 2014. p.9-12.

SCHARAGRODSKY, Pablo. Girls, women and physical activity in Argentina: past and present. The International Council of Sport Science and Physical Education (ICSSPE). Bulletin. Journal of Sport Science and Physical Education, Berlin. n.72, p.29-36, jun. 2017.

SCRUTON, Roger. The Palgrave Macmillan dictionary of political thought. London: The Macmillan Press, 2007.

SOARES, Carmen Lucia. Educação do corpo. In. GONZÁLEZ, Fernando Jaime; FENSTERSEIFER, Paulo Evaldo. Dicionário Crítico de Educação Física. Ijuí: Unijuí, 2014, p.219-225.

SOUZA, Rodrigo Augusto de. A filosofia de John Dewey e a epistemologia pragmatista. Redescrições, v.2, n.1, 2010.

STRUNA, Nancy. Sport and society in early America. The International Journal of the History of Sport, v.5, n.3, p.292-311, 1988. DOI: https://doi.org/10.1080/09523368808713664

THE ONLINE GUIDE TO TRADITIONAL GAMES. Shove Ha'penny: History and Useful Information. 2019. Disponível em: https://www.tradgames.org.uk/games/ShoveHaPenny.htm.

VARTANIAN, Aram. From deist to atheist: Diderot's philosophical orientation 1746-1749. Diderot Studies, p.46-63, 1949.

VIGARELLO, Georges. Exercitar-se, jogar. In: VIGARELLO, Georges; CORBIN, Alain; CORTINE, Jean-Jacques. História do corpo 1 - Da Renascença às Luzes. Petrópolis: Vozes, 2008. p.303-399.

WATSON, Nick; WEIR, Stuart; FRIEND, Stephen. The development of muscular Christianity in Victorian Britain and beyond. Journal of Religion and Society, v.7, 2005.

WEBER, Max. A ética protestante e o espírito do capitalismo. São Paulo: Companhia das Letras, 2004.

WORLD CHESS HALL OF FAME. Benjamin Franklin. 2018. Disponível em: https://worldchesshof.org/hof-inductee/benjamin-Franklin. 